Iraqi Journal of Industrial Research (IJOIR)

Journal homepage: http://ijoir.gov.iq

\title{
Could 5G Technology Be the Cause of COVID-19?
}

\author{
${ }^{1}$ Omar Alani, ${ }^{2}$ Ahmed Y. Qasim*, ${ }^{3}$ Laith Al-Jobouri \\ ${ }^{1}$ University of Salford - UK \\ ${ }^{2}$ Corporation of Research and Industrial Development - Iraq \\ ${ }^{3}$ University of Essex - UK
}

\section{Article information}

Article history:

Received: April, 19, 2021

Accepted: May, 11, 2021

Available online: June, 14, 2021

\section{Keywords:}

$5 \mathrm{G}$,

COVID-19,

Conspiracy theory

*Corresponding Author:

Ahmed Y. Qasim

ayhk66@gmail.com

DOI:

https://doi.org/10.53523/ijoirVol8I1ID41

\begin{abstract}
The burning of 5G sites across the UK in April 2020 has shocked the scientific and industrial society in the UK. The UK's mobile networks have reported 20 cases of masts being targeted in suspected arson attacks over the Easter weekend [1]. The attacks have been driven by conspiracy theories, which claim that the deployment of $5 \mathrm{G}$ networks has caused or helped accelerating the spread of COVID-19. But scientists say the connection between COVID-19 and 5G is a "complete nonsense" and biologically impossible. This article discusses the claims about $5 \mathrm{G}$ technology and its link to COVID-19 and will make a conclusion whether conspiracy theories have any ground. Our fact checking investigation lead to the conclusion that any claims connecting this technology to the pandemic are false. Inversely, the huge capabilities offered by $5 \mathrm{G}$ especially with IoT and AI that could be used to revolutionize the healthcare sector by providing better assistance to the frontline staff, and facilitating improved virus tracking, patient monitoring, data collection, and analysis.
\end{abstract}

\section{Introduction}

$5 \mathrm{G}$ refers to the fifth generation of wireless communication technology supporting mobile networks globally [2]. 5G uses higher carrier frequency at millimetre wave (mmWave) band from 3 to $300 \mathrm{GHz}$. Due to the availability of large amount of unused spectrum [3], more devices will be allowed to have access to the internet at the same time and at faster speeds.

5G promises to fulfil extreme user demands and to achieve massive network capacity and connectivity and will facilitate smart technologies [4]. It also accommodates and gives links to other technologies like Internet of Things (IoT) and Artificial Intelligence (AI). It provides better performance in terms of higher speed, lower latency, increased availability, and more reliability compared to $4 \mathrm{G}$ and other systems. Since $5 \mathrm{G}$ uses high frequency millimetre wave, these waves are susceptible to high power loss when travel through obstacles. Therefore, they travel shorter distances in urban areas. Hence, the network requires more transmitter masts than previous technologies, and should be located at low ground level. More transmitters per unit area means longer and more frequent exposure of human body to radiation. 


\section{Frequency Ranges for $\mathbf{5 G}$}

In the UK, Office of Communications (Ofcom) has allocated 3 different bands for the $5 \mathrm{G}$ technology, these bands are $700 \mathrm{MHz}, 3.4-3.8 \mathrm{GHz}$ and $26 \mathrm{GHz}$ [5]. The 3.4 were auctioned for $5 \mathrm{G}$ but the $700 \mathrm{MHz}$ and part of the $3.4-3.8$ GHZ (3.6-3.8 GHz) were scheduled to be auctioned in November 2020 due to COVID-19, with no date for $26 \mathrm{GHz}$ [6]. Therefore, all frequencies that use for $5 \mathrm{G}$, have been already used in the past and no one complained about it or about the frequencies had been used. The other issue is that the $26 \mathrm{GHz}$ is not a millimetre wave signal (the cause of danger to human), but in fact the millimetre wave is starting at $29.979 \mathrm{GHz}$ frequency and beyond. This frequency is a Non-Ionising Radiation (NIR), which is considered safe in frequency spectrum.

\section{Stand Alone (SA) and Non Stand Alone (NSA)}

$5 \mathrm{G}$ is working on two approaches, the first one is the Non Stand Alone (NSA), which depends on 4G network somehow. The second approach is the Stand Alone, where the whole system is based on the 5G network as shown in Figure (1) [7]. All the operators in the UK are working with NSA mode and not with SA mode for now.

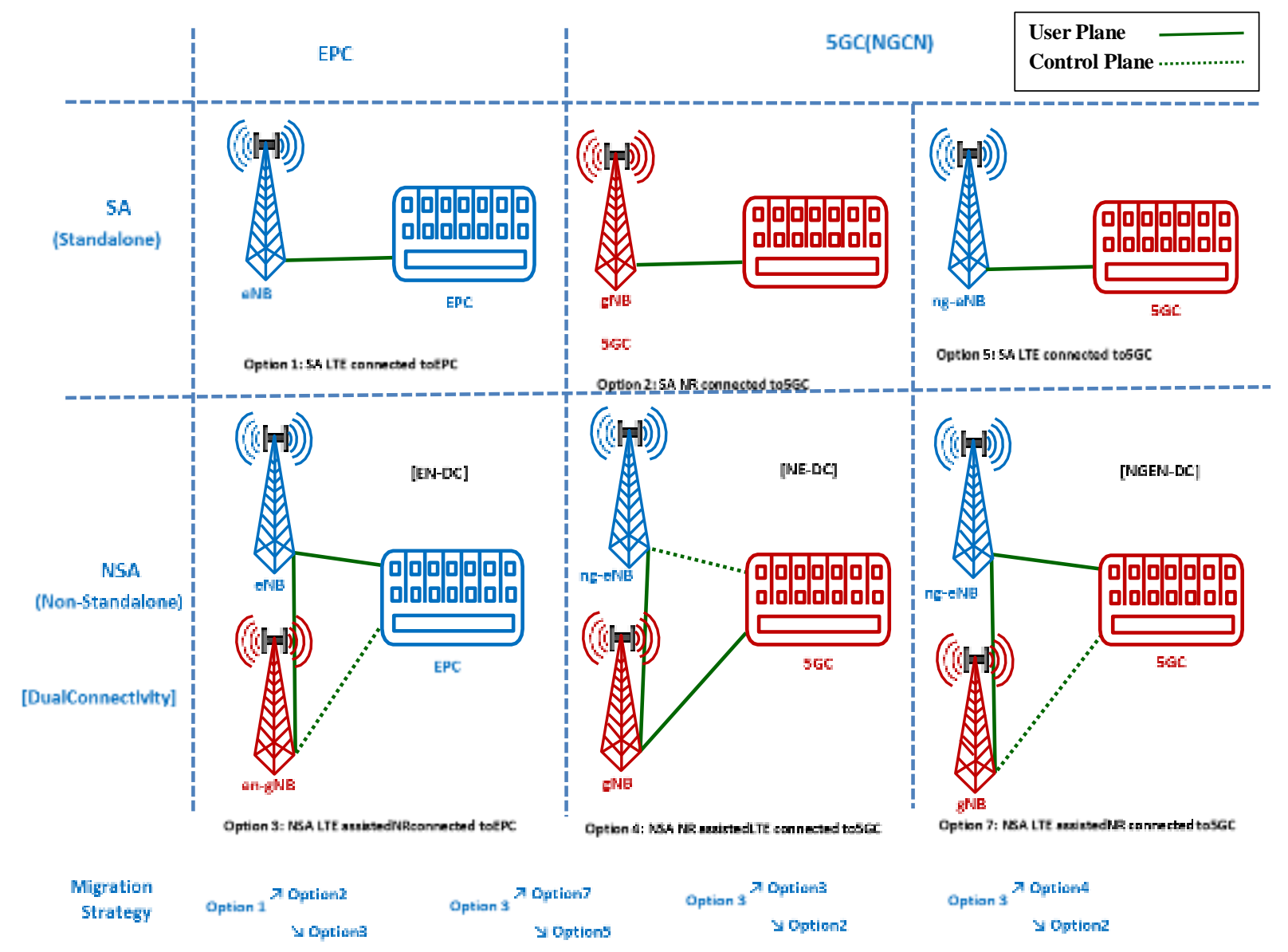

Figure (1). NSA and SA two approaches in 5G (Source: 3G4G).

\section{Fixed Wireless Access (FWA)}

5G adapts the Fixed Wireless Access (FWA) techniques to minimize the use of the millimetre waves in the 5G networks. Basically FWA will carry 5G signal to the buildings from the 5G network to overcome the short distance coverage of the high frequencies in $5 \mathrm{G}$ systems as in Figures $(2 \& 3)$. Inside the building, the network uses Customer Premises Equipment to spread the network through Wi-Fi router [7]. 

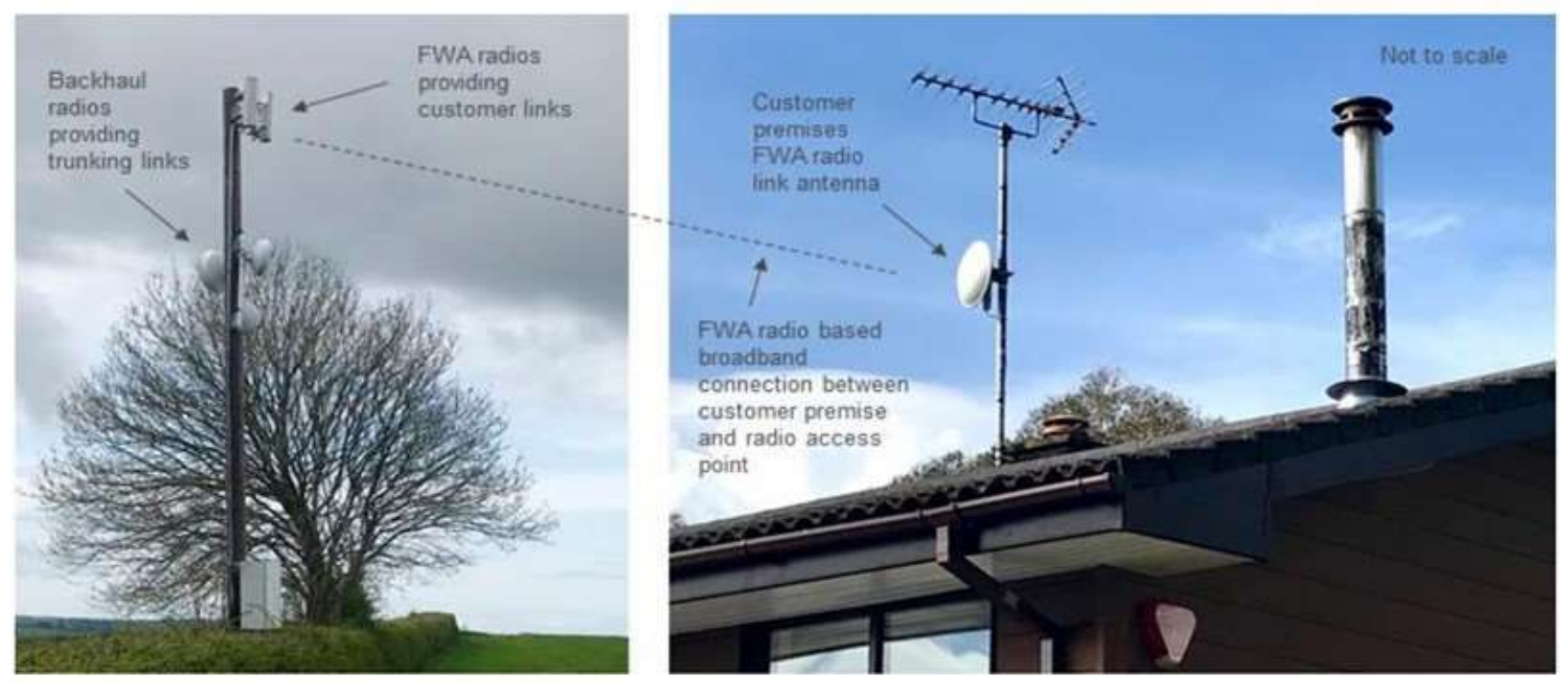

Figure (2). Outdoor to Outdoor FWA (Source: Plum Consulting Whitepaper on FWA).

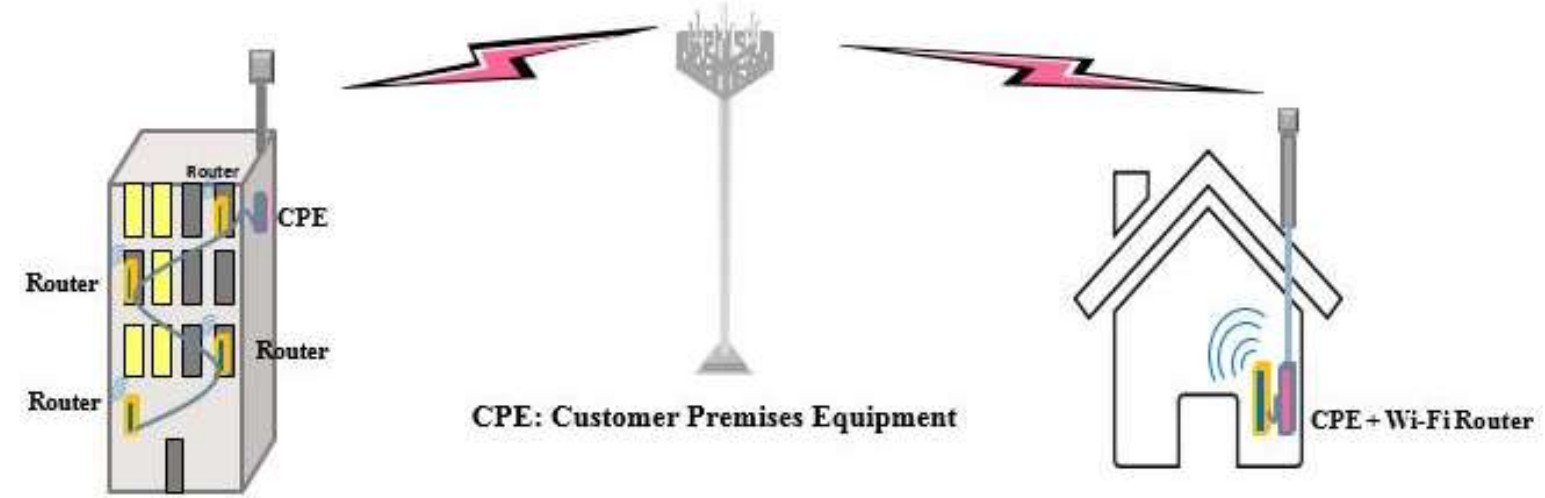

Figure (3). Outdoor to Indoor FWA.

\section{The biological link}

One of the conspiracy theories about the link between 5G and COVID-19 suggests that 5G suppresses the immune system. The other conspiracy theory claims that the virus is somehow using the network's radio waves to communicate and picks victims, to accelerate its spread [1]. The latter theory appears to be based on the work of a Nobel Prize-winning biologist who suggested that bacteria could generate radio waves. The measurements of bacterial radio waves were published in 2009 by Luc Montagnier, who won the Nobel Prize for medicine in 2008 for the discovery of HIV. However, Montagnier is a controversial figure and it is fair to say that his claims are not accepted by most mainstream biologists [8].

In any case, COVID-19 is a virus rather than a bacteria and scientific and health communities have strongly rejected these theories describing them as "complete rubbish" according to Dr Simon Clarke, associate professor in cellular microbiology at the University of Reading. While the conspiracy theories have been named "the worst kind of fake news" by National Health Service NHS England Medical Director Stephen Powis [9]. So, having ruled out the above conspiracy theories about $5 \mathrm{G}$ connections to the Coronavirus pandemic, is there still any danger from $5 \mathrm{G}$ networks? to answer this question, one has to look at the fundamentals of mobile systems operation, these systems include $5 \mathrm{G}$ transmit radio waves and there is an old dispute about whether or not radio wave poses health risk to human.

Generally speaking, it is the high band frequencies that have caused most concern. Although, ongoing worries about $2 \mathrm{G}, 3 \mathrm{G}$ and $4 \mathrm{G}$, which use the low and mid part of the range, have not subsided as shown in Figure (4). 


\section{Radio Waves}

Research about radio wave risk to human considered other types of effects, such as the potential development of cancer in the human body as a result of exposure to radio waves.

Earlier in this year (2020), a long-running study from the watchdog the International Commission on Non-Ionizing Radiation Protection (ICNIRP) rebutted these claims, saying there was no evidence that mobile networks cause cancer or other illnesses [10].

According to Professor Rodney Croft, adviser to the International Commission on Non-Ionizing Radiation Protection (ICNIRP), there is no 5G cancer risk, as the levels of mmWave used for 5G (and earlier mobile technologies) are so low that the heating effects are not harmful.

In contrast to $\mathrm{X}$ and Gamma rays, the radiation of the radio wave band - used for mobile phone networks - is a non-ionising, "which means it lacks the sufficient energy required to break apart DNA and cause cellular damage,"says David Robert Grimes, physicist and cancer researcher from Queen's University Belfast, in the United Kingdom".

Higher up the electromagnetic spectrum, well beyond those frequencies used by mobile phones, there are clear health risks from extended exposure. The major health concern is the heat increase of the human tissue due to the absorption of EMF energy.

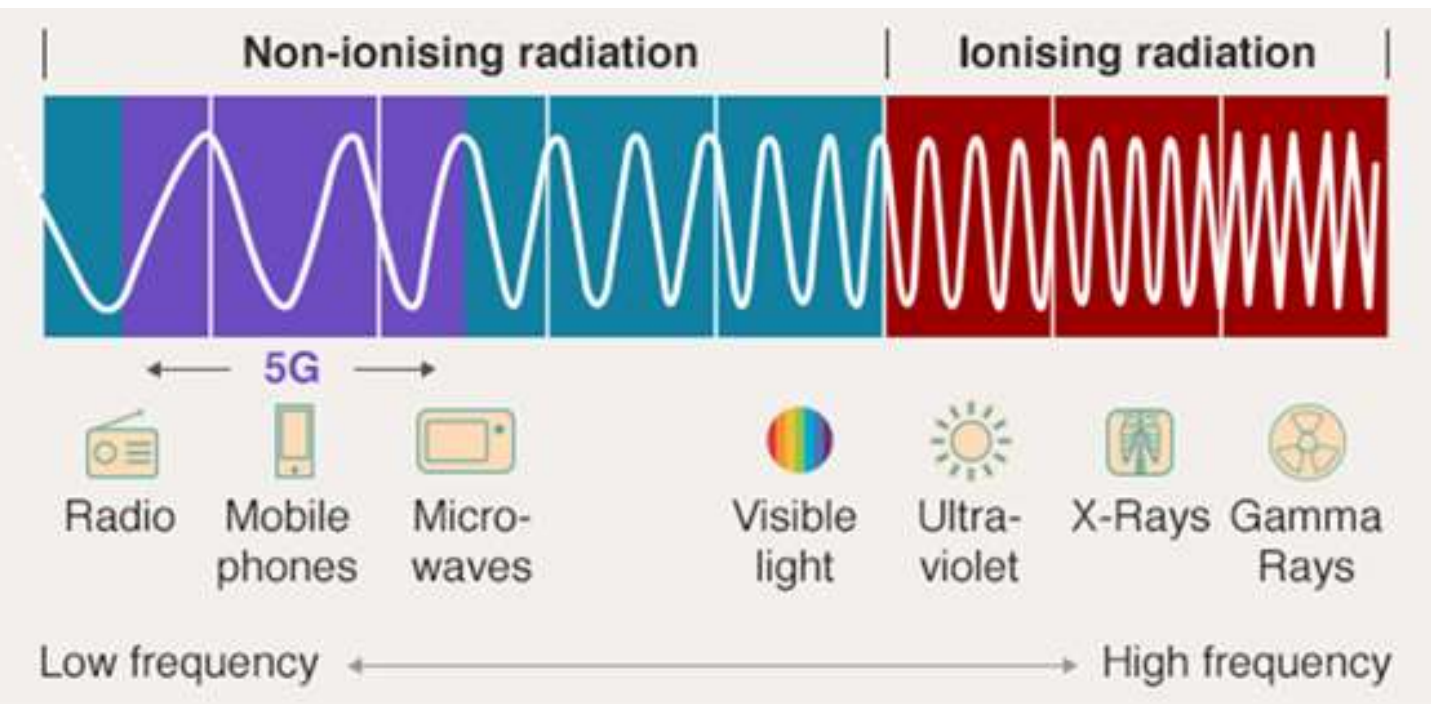

Figure (4). Location of 5G in the Electromagnetic Spectrum Source: SCAMP/ Imperial College London/EBU.

The study of NIR of mmWave is related to the interaction of EMF with human biological systems. The mmWave transmission should comply with the standard exposure guidelines before they are released for commercial use. The Federal Communications Commission (FCC) and the International Commission on Non-Ionizing Radiation Protection (ICNIRP) are the two international bodies that are responsible for setting the regulations and standards in this area.

One of the solar radiations is the Ultraviolet (UV) radiation which is considered natural and has a frequency band of much higher than that of $5 \mathrm{G}$ bands. Other artificial sources of UV are tanning beds, and electric arc lighting. The UV radiation helps to produce vitamin D and the World Health Organization (WHO) recommends people to be exposed to sunlight for 5 to 15 minutes in 2 to 3 times a week to have enough vitamin D. Exposing to UV radiation for too long can cause the following:

1. Skin cancer.

2. Eye damage. 
3. DNA damage.

4. Burns.

5. Premature aging of the skin.

Ultraviolet radiation is responsible for the majority of skin cancers; while using tanning beds and tanning devices increase the chance of developing skin cancer [11].

\section{Is 5 G dangerous?}

Despite the huge amount of research on $5 \mathrm{G}$, it is still not easy to decide whether or not this technology is harmful. Influenced by social media communication to the most exciting and alarming stories to the people it becomes even more difficult to decide on this.

However, one thing to remember, while $5 \mathrm{G}$ uses different radio frequencies to its predecessors, it is important to recognise that the waveband involved is still "non-ionising", meaning it does not have enough energy to break apart chemical bonds in the DNA in our cells to cause damage. According to Institution of Engineering and Technology (IET) report [12], they reached a conclusion, which shows that 5G is safe as GSM, 3G and 4G.

\section{Can 5G help in fighting COVID-19?}

The answer is yes, the huge capabilities offered by $5 \mathrm{G}$ especially with IoT and AI that could be used to revolutionize the healthcare sector by providing better assistance to the frontline staff, and facilitating improved virus tracking, patient monitoring, data collection, and analysis. The commercialization of 5G technology in China has already transformed China's response mechanism to the COVID-19 pandemic [13]. Chinese telecommunications operator, China Mobile, has provided six 5G-enabled intelligent robots to the Shanghai Public Health Clinical Center. These robots perform a multitude of operations, such as sanitizing premises and delivering medicines to the patients, to name a few, also 5G thermal imaging cameras and 5G health monitors have been deployed by the telecom operator in their bid to combat the coronavirus crisis [14].

A local robotic company in China, has recently designed 5G police patrol robots, these smart robots have been used in AI, IoT, 5G, and cloud computing technologies, and equipped with five infrared thermometers \& highresolution cameras that allow them to measure the body temperatures of up to 10 people at once. Furthermore, by employing the use of environmental sensing, these robots can also determine if someone is wearing a mask or not and sends an alert to the local authorities [15].

We are still expecting more from 5G technologies in the future to help in fighting diseases and pandemics, areas such as Telemedicine, medical imaging, thermal imaging and robots are hot areas where to expect big contributions from $5 \mathrm{G}$ technologies.

\section{Conclusions}

There are so much that have been said about the relationship between 5G and COVID-19, some hostile activities have also been committed against 5G telecom infrastructure blaming it for the pandemic. In this article we examined these claims and presented a fact check findings about whether the $5 \mathrm{G}$ technology could be the cause of the pandemic. By reviewing experts' opinions, as well as, known scientific facts about radio waves at high frequency (millimeter wave), we are able to confidently disprove claims of any kind of $5 \mathrm{G}$ relations to the origin of the COVID-19. The spread of conspiracy claims and similar rumors have been flared by misinformation circulating in different social media platforms by regular people. This shows the extent of influence these platforms have in shaping the general public opinions about any issue, and the need to regulate its operation and usage in accordance to the law and public safety regulations.

\section{References}

[1] BBC News, April 2020, Available: https://www.bbc.co.uk/news/technology-52281315.

[2] 218 "What is 5G: Everything you need to know about 5G: 5G faq," 2020. [Online]. Available: https://www.qualcomm.com/invention/5g/what-is $5 \mathrm{~g}$. 
[3] N. Al-Falahy and O. Y. K. Alani, "Millimetre Wave Frequency Band as a Candidate Spectrum for 5G Network Architecture : A Survey," Elsevier Phys. Commun., Vol. 32, DOI:10.1016/j.phycom.2018.11.003, pp. 120244, 2019.

[3] 3 ITU, "Minimum requirements related to technical performance for IMT-2020 radio interface(s)," Work Party5D, Vol. November, No. 5D/TEMP/300(Rev.1), pp. 1-148, 2017.

[4] Ofcom (2019), available: https://www.ofcom.org.uk/about-ofcom/latest/media/media-releases/2019/releasingairwaves-for-mobile-services.

[5] 5G, Available: https://5g.co.uk/guides/5g-frequencies-in-the-uk-what-you-need-to-know/.

[6] 3g4g, Available: https://www.3g4g.co.uk/Training/.

[7] Kevin Bullis, MIT Technology review, Energy Highlights, April 25, 2011 Available: https://www.technologyreview.com/2011/04/25/195119/energy-highlights/.

[8] BBC News available: https://www.bbc.co.uk/news/world-europe-48616174.

[9] Artificial tanning devices, Public health interventions to manage sunbeds, World Health Organization, (2017) available: https://apps.who.int/iris/bitstream/handle/10665/255695/9789241512596-eng.pdf?sequence=1.

[10] BBC News April 2020, Available: https://www.bbc.co.uk/news/technology-51839681.

[11] IET (2020), available: https://www.theiet.org/media/6248/allaying-health-concerns-regarding-5g-andexposure-to-radio-waves-2nd-edtion.pdf.

[12] Q. Xiaoxia, "How emerging technologies helped tackle COVID-19 in China," Apr 2020. [Online]. Available: https://www.weforum.org/agenda/2020/04/how-next-generationinformation-technologies-tackled-covid-19in-china/.

[13] M.Xuequan,"Shanghaiuses5grobotsonfrontlinetocombatcovid-19," Mar2020, [Online]. Available: http://www.xinhuanet.com/english/202003/01/c_138833060.htm.

[14] J. Happich, "5G edge patrol robots deployed in China to detect Covid-19 cases," Mar 2020. [Online]. Available: https://www.eenewseurope.com/ news/5g-edge-patrol-robots-deployed-china-detect-covid-19cases. 